\title{
LAPAROSCOPIC TREATMENT OF LIVER HYDATID DISEASE
}

\author{
Georgi Ivanov', Valentin Ignatov ${ }^{1}$, Nikola Kolev' ${ }^{1}$ Anton Tonev', Vilian Platikanov ${ }^{2}$, \\ Aleksandar Zlatarov ${ }^{1}$, Krasimir Ivanov ${ }^{1}$ \\ ${ }^{1}$ First Clinic of Surgery, ${ }^{2}$ Department of Anesthesiology and Intensive Care, \\ St. Marina University Hospital of Varna
}

\begin{abstract}
Surgical treatment has been considered the only available treatment of liver hydatid disease because of the complete removal of the parasite. According to the new standards for clinical approach to hepatic hydatid disease, there is no golden rule and the individual approach to every patient and cyst is of greatest importance. The laparoscopic method in the treatment of liver hydatid disease includes complete excision of the cyst, unroofing, evacuation and obliteration of the cyst cavity. Some authors perform a direct exploration of the cyst cavity in order to reject or confirm the presence of the communication of the cyst with the biliary tree. The laparoscopic method has advantages as a minimally invasive method with shorter hospital stay and minimal risk of wound complications. All the arguments prove the laparoscopy to be feasible and effective method of treatment of liver hydatid disease.
\end{abstract}

Key words: liver hydatid disease, laparoscopic surgery, advantages, indications, data-bases

\section{INTRODUCTION}

Surgical treatment has been considered the only available treatment of liver hydatid disease because of the complete removal of the parasite. Nowadays, except for surgery, the clinical approach to the disease includes several therapeutic methods varying from adjuvant therapy with benzoimidazole carbamates such as mebendazole and albendazole to percutaneous treatment such as PAIR (11). According to the new standards for clinical approach to hepatic hydatid disease, there is no golden rule and the individual approach to every patient and cyst is of greatest importance $(11,14)$. The surgical method

Address for correspondence:

G. Ivanov, $M D$

First Clinic of Surgery,

St. Marina University Hospital of Varna

1 Hristo Smirnenski Str., 9010, Varna, Bulgaria

E-mail:ghivanov@abv.bg

Received: August 30, 2012

Accepted: January 15, 2013 is considered the method of choice for liver hydatid disease for many years. Its main goal is to inactivate the scolexes, to prevent dissemination in the abdominal cavity and to obliterate the remaining cavity. Several surgical methods have been introduced to obliterate the remaining cavity being related to a high risk of postoperative complications. This is the reason why some surgical methods such as marsupialization are not used anymore (10).

\section{MATERIAL AND METHODS}

We performed retrospective problem-oriented literature searches in the following data bases: ScienceDirect, SCOPUS, Web of Knowledge, InCities, and MEDLINE (PubMed version) using the indexing terms of 'echinococcosis', 'hydatid disease', 'liver', 'echinococcal cyst' and 'Laparoscopic treatment' during the period 1995-2012. Here we present the current laparoscopic techniques, the advantages and disadvantages of the method as well as its indications and contraindications. 


\section{RESULTS}

The laparoscopic method in the treatment of liver hydatid disease consists in complete excision of the cyst, unroofing, evacuation and obliteration of the cyst cavity $(3,4)$. Its advantages include a minimal invasion with shorter hospital stay and minimal risk of wound complications (6). The method provides an option for detailed overview of the cyst cavity (7).

On the other hand, to the disadvantages of the laparoscopic approach belong limited opportunities for surgical procedures, difficult control during the cyst puncture and aspiration of the contents, e. g. danger of peritoneal dissemination $(3,6,7)$. The localization of the cyst and the presence of complications create technical difficulties in performing the procedure (6). However, many authors recommend this method $(3,6,7)$.

It is done by entering through the abdominal wall trocar port leakage of gas $\left(\mathrm{CO}_{2}\right)$ to create pneumoperitoneum. Similar techniques like those in aseptic conventional surgery are applied $(3,7)$. Patient's position, number and locations of ports vary by the location and size of hydatid cysts (3). Usually, the surgeon stands between the patient's legs raised in Y-position, or on the left side of the patient if cysts are in the right lobe of the liver. The procedure starts with a diagnostic laparoscopy to visualize the cyst $(3,6,7)$. Then a decompression of the cyst by aspiration of the cystic fluid is performed. After aspirating the maximal amount of fluid in the cavity, equal volume hypertonic sodium chloride solution is instilled followed by standing for 5-10 min, according to different authors, to repeat aspiration $(3,7)$. After sterilization of the cavity incision or excision of part of pericyst (anrufing) germinal layer of hydatid is performed and appendages are removed (3).

Some authors explore directly the cyst cavity in order to reject or confirm the presence of the communication of the cyst with the biliary tree (7). The residual cavity is treated by obliteration performed by means of omentum or entering the drainage catheter $(3,6,7)$.

Major complications during laparoscopic access are spilling cyst contents into the abdominal cavity and leakage from the biliary system $(6,7)$. When the patients are not properly selected, access is inappropriate and imaging is insufficient, conversion rate significantly increases, especially in the patients with abnormalities or variations in the intervention (3). According to the literature available, in Denmark recurrence after laparoscopic surgery occurs in $2-3 \%$ of the patients within six months after the intervention.The possibility of developing recurrent disease is not directly correlated with errors of the operative approach or intraoperative complications such as dissemination of cysts fluid in the abdomen $(3,7)$.

Contraindications for laparoscopic surgery are:

1. Acute cardiopulmonary failure that incompatibly induces pneumoperitoneum with $\mathrm{CO}_{2}(3,6,7)$.

2. Previous abdominal surgery which involves adhesions, thereby reducing visibility and complicating the procedure (7).

3 . Recurrent hydatid cysts $(3,7)$.

4. Cyst located more than $1 \mathrm{~cm}$ in depth from the hepatic surface can hinder diagnosis and carries the risk of significant bleeding when liver parenchyma is cut by standard laparoscopic staff $(3,6,7)$.

\section{DISCUSSION}

Minimally invasive methods are of rising importance in contemporary surgery. The laparoscopic approach was introduced in 1991 by Khoury et al. (cited after 12) and in 1992 by Acunas et al. (cited after 2). Hiowever, the laparoscopic method is still of limited use. According to the experience of Bastid et al. (4), the treatment is good for cyst with thin wall of type I, II and III after Gharbi's classification. No complications are observed and the postoperative stay is $24-72$ hours. A larger series $(\mathrm{n}=33)$ by Alper et al. (1) demonstrates 11 patients unsuitable for laparoscopy due to multiple localization or recurrence after conventional treatment and another 22 ones, who are treated laparoscopically. In the second group, six patients are converted to open surgery due to adhesions or difficultly accessible localization.

The surgical area should be protected with scolicidal solutions to prevent dissemination in case of leakage from the cyst. The solutions of choice are 
hypertonic saline of $30 \%$ and peroxide solution of $10 \%$ o. The latter has many disadvantages due to its effervescent effect that may cause cyst rupture into the peritoneal cavity or, in case of biliary fistula, sclerosis of the biliary tract and papilla Vateri. The postoperative period is shorter when compared to open surgery (8-10 days).

However, the risk of allergic and anaphylactic reactions persists. The recurrences after leakage can be prevented by preoperative administration of scolicidal agents (e. g. mebendazole and albendazole). Gil-Grande et al. demonstrate that after one month 72 per cent of the cysts are already sterilized and after 3 months there is an increase up to 93 per cent $(8,9)$. In another study (1) the drug is administered 10 days preoperatively and 3 months postoperatevely. There are no recurrences at all.

Several laparoscopic techniques are described in the literature. One of the goals is the removal of the germinative membrane. The most preferred procedure is laparoscopic aspiration of the cyst and, eventually, partial cystectomy (16). Some authors recommend the use of large-bore suction catheter (13). Other authors recommend obliteration of the cyst cavity with omentoplasty in order to reduce complications. Ertem et al. (5) use stapler device to fix the omentum to the capsule. The surgeon must avoid injury to the liver at this stage.

The deep localization of the hydatid cysts represents one of the limitations of the laparoscopic approach. The surgeon must avoid contact of the cystic fluid with the blood to prevent anaphylactic shock and thus, in this case, the open surgery has the advantage over laparoscopy.

The laparoscopic surgery is contraindicated in the case of biliary communication, which could be diagnosed with preoperative MR cholangiography or endoscopic retrograde cholangiography.

\section{CONCLUSION}

The laparoscopic surgery has several advantages of a minimally invasive method with shorter hospital stay and minimal risk of wound complications. It provides an option for detailed overview of the cyst cavity. Patient's social and professional reintegrations are more accelerated than following the conventional open surgery. The laparoscopic surgery undoubtedly plays a key role in the treatment of liver hydatid disease. Therefore, it should be recommended for a wider application in the clinical practice.

\section{REFERENCES}

1. Alper, A., A. Emre, K. Acarli, O. Bilge, I. Ozden, O. Ariogul. Laparoscopic treatment of hepatic hydatid disease.- J. Laparoendosc. Surg., 6, 1996, No 1, 29-33.

2. Avgerinos, E. D., E. Pavlakis, A. Stathoulopoulos, E. Manoukas, G. Skarpas, P. Tsatsoulis. Clinical presentations and surgical management of liver hydatidosis: our 20 year experience.- HPB (Oxford), 8, 2006, No 3, 189-193.

3. Baltar Boilève, J., I. Baamonde De La Torre, P. Concheiro Coello, L. A. García Vallejo, J. Brenlla González, B. Escudero Pérez, et al. Laparoscopic treatment of hepatic hydatid cysts: techniques and post-operative complications.- Cir. Esp., 86, 2009, No 1, 33-37 (in Spanish).

4. Bastid, C., C. Azar, M. Doyer, J. Sahel. Percutaneous treatment of cyst under sonographic guidance.- Dig. Dis. Sci., 39, 1994, No 7, 1576-1580.

5. Ertem, M., C. Uras, T. Karahasanoglu, S. Erguney, K. Alemdaroglu. Laparoscopic approach to hepatic hydatid disease.- Dig. Surg., 15, 1998, No 4, 333-336.

6. Foster, E. N., G. Hertz. Echinococcus of the liver treated with laparoscopic hepatectomy.- Perm. J., 14, 2010, No 2, 45-46.

7. Gastaca, M., A. Ventoso, J. González, J. Ortiz De Urbina. Laparoscopic surgery of hepatic hydatid cyst.- Cir. Esp., 88, 2010, No 1, p. 62; author reply, p. 64 (in Spanish).

8. Gil-Grande, L. A., D. Boixeda, L. Ledo. Tratamiento actual de la hydatidosis humana.Enferm. Infect. Microbiol. Clin., 5, 1987, 627-632.

9. Gil-Grande, L. A., F. Rodriguez Caabeiro, J. G. Prieto, J. J. Sánchez-Ruano, C. Brasa, I. Aguilar, et al. Randomised controlled trial of efficacy of albendazole in intraabdominal hydatid disease.Lancet, 342, 1993, No 8882, 1269-1272.

10. Goldin, S. B., J. J. Mateka, M. J. Schnaus, S. Dahal. Laparoscopic drainage of a hepatic echinococcal 
cyst: a case report.- Case Rep. Gastrointest. Med., 2011; 2011:107087. doi: 10.1155/2011/107087.

11. Hidalgo, M., E. Ferrero, J. Perea, A. Hidalgo. Liver hydatidosis in the present decade.- Rev. Esp. Enferm. Dig., 103, 2011, No 9, 445-447.

12. Khoury, G., S. Jabbour-Khoury, K. Bikhazi. Results of laparoscopic treatment of hydatid cysts of the liver.- Surg. Endosc., 10, 1996, No 1, 57-59.

13. Palanivelu, C., K. Jani, V. Malladi, R. Senthilkumar, P. S. Rajan, K. Sendhilkumar, R. Parthasarthi, A. Kavalakat. Laparoscopic management of hepatic hydatid disease.- J. Soc. Laparoscop. Surg., 10, 2006, No 1, 56-62.
14. Ramia Ángel, J. M., J. E. Quiñones Sampedro, R. Puga Bermúdez, P. Veguillas Redondo, J. GarcíaParreño Jofré. Use of a laparoscopic trocar for the removal of hepatic hydatid cysts.- Cir. Esp., 90, 2012, No 1, 60-61 (in Spanish).

15. Saglam, A. Laparoscopic treatment of liver hydatid cysts.- Surg. Laparosc. Endosc., 6, 1996, No 1, 16-21.

16. 16. Seven, R., E. Berber, S. Mercan, L. Eminoglu, D. Budak. Laparoscopic treatment of hepatic hydatid cysts.- Surgery, 128, 2000, No 1, 36-40. 